\title{
The Role of the Palermo Documents
}

\author{
UN Trafficking Documents: Overview
}

In late 1990s, efforts against transnational organized crime were undertaken at the international level. States agreed that organized crime was becoming increasingly internationalized, which required international responses. To this end, the Palermo documents were drafted. ${ }^{1}$ This chapter contains an analysis of the Palermo documents, i.e., the Palermo Convention and the Palermo Protocol on trafficking. ${ }^{2}$ It describes the documents' importance and their mutual relation as well as by whom, why, and when they were drafted. Firstly, the Palermo Protocol is considered in its specific setting, taking into account the drafting process as well as the document's historical context. This is carried out according to the concept of legal transplants, more specifically the factor of transmissibility.

Secondly, the legal content of the documents is analysed. Emphasis is on the definition of trafficking as stated in Article 3 of the Palermo Protocol. Specific issues of interest, i.e., issues that might affect the national implementation process, are identified.

As has been mentioned above, trafficking in human beings affects highly politicized areas such as migration, labour, prostitution, etc. It therefore necessarily involves various perspectives and stakeholders with often disparate priorities. This disparity makes the crime difficult to tackle not only on the national but also on the international level. Also, the crime is a multinational problem. It therefore requires a holistic and international response. This response in turn must be supported and reinforced on the regional and national level. As has been mentioned above, the international community (e.g., the UN, EU, etc.) has agreed that a common definition of the crime is a first step toward progress in this specific area. If we are to address and compare something, one of the first steps is agreeing on what it is, and here is where the Palermo Protocol's definition of trafficking enters into play.

1 These documents include the UN (Palermo) Convention on Transnational Organized Crime and the Protocols thereto. The protocols address trafficking in human beings, smuggling in human beings, and the illicit manufacturing of and trafficking in firearms.

2 The other protocols that adjoin the Palermo Convention are not of importance in this context.

(C) KONINKLIJKE BRILL NV, LEIDEN, 2015 | DOI 10.1163/9789004281073_005

This is an open access chapter distributed under the terms of the prevailing CC-BY-NC License at the time of publication. 
Notwithstanding the fact that individual countries struggle with certain problems that might hamper anti-trafficking efforts on the national level, the international definition arguably has some potential to improve the overall situation in this area. Conversely, a troublesome situation cannot improve if we are working with an inadequate international definition of trafficking. This does not mean that the situation is not complicated, because it is. There are many problems, both national and international. However, we must start somewhere.

The international community has attempted to tackle the problem of human trafficking for over a century. ${ }^{3}$ In that sense, the Palermo Protocol is not a novelty. However, the document does differ from its predecessors. The most important difference from previous international documents in this area is that the protocol sets out specific obligations vis-à-vis the state signatories. The parties to the protocol are obligated to criminalize the offences established therein. Although a verbatim transposition of the international definition of human trafficking into national laws is not officially required, state signatories are nevertheless required to get their laws in line with that definition.

In order to be able to understand some of the difficulties concerning the implementation of the international definition of trafficking into national legislation, we first need to acquaint ourselves with the Palermo Convention on organized crime. This is the result of the fact that the protocol is to be interpreted in light of the Palermo Convention. Moreover, it is important to note that states cannot become party to the protocol if they do not first sign and ratify the convention. There are two or, if the Interpretative Notes ${ }^{4}$ are included, three relevant documents in this specific area, i.e., the Palermo Convention, Protocol, and Interpretative Notes. ${ }^{5}$ Certain questions emerge with regard to issues that have been addressed by these documents. These questions have had consequences for the implementation of the international trafficking definition into national legal systems. They concern:

3 A. Jonsson, D. Borg, "International Efforts to Combat Human Trafficking" in F. Shanty (edt.), Organized Crime: An International Encyclopedia, Oxford, ABC-CLIO, 2007, pp. 391-394.

4 These constitute the preparatory works to the Palermo documents. A/55/383/Add.1 Addendum, https://www.unodc.org/unodc/en/treaties/CTOC/background/General-Assembly -documents.html, (accessed 19 May 2014).

5 A. Jordan, "The Annotated Guide to the Complete un Trafficking Protocol", Global Rights. Partners for Justice, Washington, 2002, preface. 
a) Border crossing and involvement of an organized crime group when committing trafficking;

b) Intent of the perpetrator vis-à-vis the exploitation;

c) The multitude and mutual relation of various improper means;

d) Consent of the victim.

These questions will be addressed in the following, but first the original source itself will be analysed in relation to the factor of transmissibility. We will start by placing the document in its specific cultural and historical setting.

\section{Anti-Trafficking Efforts of the UN - A Historical Background}

Even though the doctrine on trafficking in human beings has been developed in international law for some time now, it was not until the beginning of the twenty-first century that a consensus on the definition of the crime emerged. The attempts that were made by the drafters of the Palermo Protocol to create an internationally binding definition notwithstanding, I shall argue that there is as of yet no common understanding of the trafficking phenomenon. The denominators that most definitions of trafficking are said to have in common concern the elements of coercion and border crossing, ${ }^{6}$ but even these concepts are subjects of frequent debates. Although discussions in this area often relate to the way in which trafficking is conceptualized, e.g., as a migration issue or as a human rights violation, the discussions preceding the adaptation of the Palermo Protocol to a large extent focused on the consent of the victim. These discussions in turn influenced the drafting process of the protocol as well as the definition of trafficking that eventually emerged. ${ }^{7}$

The first international instruments on trafficking in human beings were exclusively concerned with trafficking in women and girls for the purpose of prostitution. As a result of the international efforts to eradicate human trafficking, a document called the International Agreement for the Suppression of the White Slave Traffic was signed on 18 May 1904. The signatories, consisting of twelve European powers, among them Russia, declared that the purpose of the document was to guarantee women and girls who had been subjected to the abuse or compulsion associated with trafficking protection against the

6 K. Abramson, "Beyond Consent, Toward Safeguarding Human Rights: Implementing the United Nations Trafficking Protocol", Harvard International Law Journal, vol. 44, no. 2, 2003, p. 473 .

7 Ibid, p. 474. See more about the drafting process of the Palermo Protocol in the following. 
criminal practice of the 'white slave trade'. The preamble of the agreement read:

[....] being desirous of securing to women of full age who have suffered abuse or compulsion, as also to women and girls under age, effective protection against the criminal traffic known as the 'White Slave Traffic', have decided to conclude an Agreement with a view to concerting measures calculated to attain this object.

This suggests that women and girls in general as well as women who were already victims of trafficking were to be guaranteed protection. It has been questioned, however, whether cases involving women who were already engaged in prostitution and then forced into trafficking would fall under the scope of this provision. ${ }^{8}$ Women who might have initially consented to prostitute themselves abroad were arguably not considered as worthy of state protection as the 'coerced innocents'. The agreement is said to implicitly differentiate between 'pure and innocent' women and those with prior experience of prostitution, in effect preserving the ambivalent attitude toward women engaged in forced prostitution. ${ }^{9}$ This development had practical consequences for women victims of trafficking as it reinforced the myth of female sexuality, in effect dividing women into unwilling victims and the others.

The agreement depicts prostitution as an immoral way of life, and the question is whether the women who had worked as prostitutes prior to their exploitation were also seen as immoral. In the document the state parties agreed to:

[.... have a watch kept, especially in railway stations, ports of embarkation, and en route, for persons in charge of women and girls destined for an immoral life. ${ }^{10}$

Perhaps this was just an unfortunate choice of words, the true purpose of which was to state that the exploitation was indeed immoral. However, seen in its specific context, ${ }^{11}$ the wording of the abovementioned passage suggests that one of the main purposes of the agreement was to rid societies of the immoral

8 N. Demleitner, "Forced Prostitution: Naming an International Offense", Fordham International Law Journal, vol. 18, no. 1, 1994, p. 167.

$9 \quad$ Ibid, p. 167.

10 International Agreement for the Suppression of the White Slave Traffic, Art. 2.

11 This refers to both the nature of the document, which offered no provisions on victim assistance, and to the general attitudes toward women prevalent at that time. 
practice of prostitution as opposed to actually helping victims that had been sexually exploited.

At the beginning of the twentieth century, stereotypical ideas of women were common in politics, law, church, academia, and even psychology. Sigmund Freud, whose research was very much en vogue at that time, argued that women due to their inferiority essentially had two life choices where they could find fulfilment. One was marriage and motherhood and the other was aggressive behaviour and neurosis. This popular view reinforced the ancient idea of women as having one of two natures. According to the Madonna-whore duality, women were considered essential to the process of procreation and thus to the preservation of family life, but there was also a fear of their destructive carnal nature perhaps best portrayed as the biblical seductress Eve who led Adam to the path of damnation. In order to preserve the family unit and keep communities safe, it was commonly agreed that women had to be kept within the boundaries of the private domain. ${ }^{12}$

Although prostitution was considered an immoral way of life, the state signatories offered no real assistance to the victims but made it optional for charitable organizations or private persons to provide such help if the latter were inclined to do so. Moreover, the document did not address criminal measures against traffickers. There were thus no practical provisions in the agreement above that secured for trafficking victims the protection mentioned in the preamble of the document.

[....] within legal limits, and as far as can be done, to entrust temporarily, and with a view to their eventual repatriation, the victims of a criminal traffic when destitute to public or private charitable institutions, or to private individuals offering the necessary security. ${ }^{13}$

Today, charitable organizations and the occasional philanthropist have been replaced by NGOs as states continue to attach most attention to legislative efforts and are either reluctant or unable to offer proper protection and assistance to victims of trafficking.

Voluntary return of victims of trafficking to their country of origin seems to have been preferred by the signatories to the agreement as the parties undertook to send back women who either desired to return to their home countries or who were claimed by someone who exercised authority over them. The very

\footnotetext{
12 C. Feinman, Women in the Criminal Justice System, third edition, us, Greenwood Publishing Group, 1994, p. 4.

13 International Agreement for the Suppression of the White Slave Traffic, Art. 3.
} 
words authority and claim imply that these women were not seen as individuals but rather as possessions, their fates resting in the hands of others. They could fall victim to trafficking and then possibly become re-victimized if forced to return to someone who had the right to claim them.

[.... within legal limits, and as far as possible, to send back to their country of origin those women and girls who desire it, or who may be claimed by persons exercising authority over them. ${ }^{14}$

This reinforces the argument that the main ambition of states was, and perhaps to a certain extent still is, to rid their societies of an unwanted practice and illegal migrants. ${ }^{15}$ Again, this view prevails in many modern trafficking cases as authorities in different countries are said to deport victims of trafficking without first taking the proper precautions, sometimes without even taking the victims' statements. In some countries, victims of trafficking might be arrested or deported for selling sex without any consideration of the fact that they are first and foremost victims.

The ideas expressed in the 1904 agreement were partly replicated in subsequent documents including the 1949 Convention for the Suppression of the Traffic in Persons and of the Exploitation of the Prostitution of Others. Although this document stated that prostitution was inconsistent with the dignity and worth of the human person, it also considered it to be a threat against the family unit and, by the same token, the community. The preamble of the convention reads:

Whereas prostitution and the accompanying evil of the traffic in persons for the purpose of prostitution are incompatible with the dignity and worth of the human person and endanger the welfare of the individual, the family and the community $[\ldots .$.$] .$

\footnotetext{
14 Ibid.

15 In a Swedish case from 2013, a woman was deported after having testified in a trial concerning one of the most serious cases of trafficking in Sweden. Although the perpetrators were convicted of trafficking and the woman was one of their victims, she was still deported due to the fact that she was making money in an immoral way, i.e., not only was she a victim of trafficking, that very circumstance made the state refer to her as a criminal. See "Jo skuldbelägger offer för människohandel", Stiftelsen Tryggare Sverige, 8 March 2013, http://www.mynewsdesk.com/se/pressroom/stiftelsen-tryggare-sverige/blog_post/ view/jo-skuldbelaegger-offer-foer-maenniskohandel-17633, (accessed 19 May 2014). See more on this case under the section on Sweden.
} 
The fact that there was no specific obligation for states to offer victim support might perhaps indicate that the wellbeing of the victims was not the primary concern of the drafters of and the state parties to the convention. Moreover, if the welfare of the community was considered to be at stake, we might ask why a prohibition on the purchase of sexual services in order to curb the demand side of the practice was never considered an option. Arguably, women in prostitution were, yet again, stigmatized. In effect, the invisible distinction between the coerced innocents and the undeserving women was not called into question.

Some women may be physically forced into prostitution, others may see no other choice than to prostitute themselves to earn a living. If the latter are then at a later stage forced or lured into trafficking, they should not be treated differently from the 'coerced innocents', i.e., the victims who have not prostituted themselves before or contemplated doing so. In summary, women who have at a first stage chosen to prostitute themselves and then subsequently fall victim to trafficking should not be stigmatized or discriminated against by states. If they are treated differently from other victims of trafficking, they are automatically being re-victimized. The question is if women are still being divided into these two categories.

Previous international anti-trafficking documents, e.g., the International Agreement for the Suppression of the White Slave Traffic, are, due to the reasons mentioned above, ${ }^{16}$ outdated. However, if put under close scrutiny, the contemporary discourse on trafficking, including the Palermo Protocol, reveals some similarities with those documents, notably when the idea of a stereotypical victim of trafficking is concerned. ${ }^{17}$ Current anti-trafficking instruments seem to reproduce many of the weaknesses of the earlier approaches such as a never-ending debate on the role of prostitution and consent. ${ }^{18}$

Although knowledge concerning trafficking has increased significantly since the days of the agreement and even those of the 1949 convention, the question is whether the first priorities of states, and so the motives behind relevant international legislation, have changed in any significant way. Has the concern for the wellbeing of the victim truly become more important than issues of security, criminal justice, and border control? Or does the main

16 The main reasons include the idea of women having one of two distinct natures that was arguably expressed in the document, the instance of women being referred to as commodities, and, finally, the unfortunate title of white slave traffic.

17 E.M. Bruch, "Models Wanted: The Search for an Effective Response to Human Trafficking", Stanford Journal of International Law, vol. 40, no. 1, 2004, p. 3. 
motive behind international legislation remain to be that of upholding state sovereignty and a moral way of life? Also, do victims of trafficking get the assistance that they are entitled to or are they treated as criminals and simply returned to their home countries, i.e., deported? The following sections of this work will shed some light on these very important questions, but first the Palermo Convention on Organized Crime, with which the Palermo Protocol is to be interpreted mutatis mutandis, will be described in some detail.

\section{Palermo Convention on Organized Crime}

The United Nations Convention against Transnational Organized Crime (Palermo Convention) was the culmination of efforts undertaken by the UN in the field of organized crime since the mid-199os. In 1994, the World Ministerial Conference on Organized Transnational Crime (Naples Conference) presented a political declaration and a plan of action concerning the subject of transnational organized crime. These documents in turn inspired discussions concerning the possible creation of a uniform and legally binding convention, the primary aim of which would be to harmonies counter-strategies in the area of transnational organized crime.

This ambition was put into practice in a number of meetings held by the so-called Lyon Group, a group of senior experts established by the seven major industrialized countries of the world and the Russian Federation, i.e., the G 8 . In addition, several regional meetings were held. Although certain differences in opinion arose between the participating states, they did not hinder further international cooperation. Eventually, the General Assembly appointed an Ad Hoc Committee, the task of which it was to create a proposal for a global convention against transnational organized crime.

The committee held several sessions and managed to agree on a number of provisions. The final text was presented to the General Assembly in 2000 and was at that point adopted by the assembly and opened for signature at a highlevel conference that was held in Palermo in December 2000. Below, the main characteristics of the convention, which are of relevance to the interpretation and application of the Palermo Protocol, will be touched upon.

The Palermo Convention, much like the Palermo Protocols, requires states to understand the raison d'être behind the document, especially in cases where the convention relies on the states' discretionary powers. ${ }^{19}$ This means that

19 S. Betti, "New Prospects for Inter-state Cooperation in Criminal Matters: The Palermo Convention", International Criminal Law Review, vol. 3, 2003, p. 154. 
although states do not have to implement the text of the convention into their national legislations word by word they are obligated to consider the motives or purposes of the convention.

According to Article 37, Paragraph 2 of the Palermo Convention, a party who wishes to sign the Palermo Protocol must first become party to the convention. The protocols to the Palermo Convention were not intended to be independent treaties but to supplement the convention. The signing of the Palermo Convention therefore ensures that the general provisions of the convention will be applicable in any cases that might arise under the protocols. The rationale behind the Palermo documents is that the Palermo Convention supplies general provisions while the protocols are more specific. Article 37, Paragraph 4 of the Palermo Convention states that the protocols to the convention are to be interpreted together with the convention, taking into account the purposes of the protocols. An interpretation of the Palermo Protocol therefore requires that the convention is also considered and that provisions in the protocol and in the convention that use similar or identical language are generally given similar meaning. However, an interpretation of the Palermo Protocol should also consider the purpose of the protocol. This may in some cases modify the meaning applied to the Palermo Convention.

A similar reference is also made in the Palermo Protocol. According to Article 1, Paragraph 2 of the protocol, the provisions of the convention apply mutatis mutandis to the protocol. The meaning of the phrase mutatis mutandis is clarified in the Interpretative Notes to the Palermo Protocol as meaning "with such modifications as circumstances require" or "with the necessary modifications". ${ }^{20}$ This basically means that when the provisions of the Palermo Convention are applied to the protocol, minor modifications of interpretation or application, the purpose of which is to take into account circumstances that arise under the protocol, are allowed. However, such modifications are only permitted if absolutely necessary and then only to the extent that is necessary. In certain cases, modifications have been explicitly ruled out by the drafters. ${ }^{21}$

Another important connection between the Palermo Convention and its protocol is a principle contained in Article 1, Paragraph 3 of the protocol. This article states that offenses established in accordance with the protocol are also to be considered offenses established in accordance with the convention. This principle ensures that the general provisions on mutual assistance and other

\footnotetext{
20 Paragraph 62 of the Interpretative Notes, A/55/383/Add.1, and Paragraph 17 (c) of the Legislative Guide, Part Two, p. 254.

21 Paragraph 17 (c) of the Legislative Guide, Part Two, p. 254.
} 
forms of international cooperation of the convention will also apply to the offenses established under the Palermo Protocol.

The purpose of the Palermo Convention, as spelled out in Article 1 of the document, is to promote international cooperation in order to be able to prevent and combat transnational organized crime more effectively. Article 2 of the convention sets out the definitions of various terms used in the document, such as an organized criminal group, while Article 3 stipulates the scope of application of the convention. Article 3 , Paragraph 1 reads as follows:

1. This Convention shall apply, except as otherwise stated herein, to the prevention, investigation and prosecution of:

a. The offences established in accordance with Articles 5, 6, 8 and 23 of this Convention; and

b. Serious crime as defined in Article 2 of this Convention; where the offence is transnational in nature and involves an organized criminal group.

Article 3, Paragraph 2 then goes on to describe what is meant by a transnational offence. The Paragraph reads as follows:

2. For the purpose of Paragraph 1 of this article, an offence is transnational in nature if:

a. It is committed in more than one State;

b. It is committed in one State but a substantial part of its preparation, planning, direction or control takes place in another State;

c. It is committed in one State but involves an organized criminal group that engages in criminal activities in more than one State; or

d. It is committed in one State but has substantial effects in another State.

The wording of Article 3 , Paragraph 1 of the Palermo Convention might suggest that the document applies only to crimes that are transnational in nature and involving an organized criminal group. At the same time, however, the convention requires certain offences to be established at national levels independently of their transnational nature or the involvement of an organized criminal group. This is stated in Article 34, Paragraph 2 of the convention and concerns offences established in accordance with Articles 5, 6, 8, and $23 .{ }^{22}$ The

22 Article 34(2) reads as follows: "The offences established in accordance with articles 5, 6, 8 and 23 of this Convention shall be established in the domestic law of each State Party independently of the transnational nature or the involvement of an organized criminal group as described in Article 3, Paragraph 1, of this Convention, except to the extent that Article 5 of this Convention would require the involvement of an organized criminal group". 
offences in Article 34, Paragraph 2 of the Palermo Convention include participation in an organized criminal group (Article 5), money laundering (Article 6), corruption (Article 8), and obstruction of justice (Article 23).

The question is how to interpret the provision of trafficking as contained in the protocol. Are states required to criminalize trafficking only when there is a transnational element, or do the convention and the protocol require criminalization also in non-transnational cases? There is no clear answer to this question in any of the Palermo documents. In order to find an answer, both documents as well as the preparatory works thereto must be consulted.

According to an Interpretative Note to Article 34 of the Palermo Convention, the convention requires the elements of transnationality and the involvement of an organized criminal group in relation to the provisions pertaining to international cooperation but not to the extent that the elaboration of national criminal offences is concerned. ${ }^{23}$ Although the note in question only mentions offences established in accordance with Articles 5, 6, 8, and 23 of the convention, it also states:

[...] This provision is furthermore intended to ensure clarity for States Parties in connection with their compliance with the criminalization articles of the Convention and is not intended to have any impact on the interpretation of the cooperation articles of the Convention.

This suggests that in cases of international cooperation, an element of transnationality is required. One way of reading the note might be that the elements of transnationality and organized crime group are not required in cases of national criminalization of all offences established in accordance with the convention and its protocols. It is argued that Article 34, Paragraph 2 of the Palermo Convention should be directly applicable also with regard to trafficking offences. The argument is that the same provision ought to apply to the crime of trafficking to ensure that all traffickers can be prosecuted under national laws. ${ }^{24}$ Again, there are no clear indications in the Palermo Convention or the protocol that the statement above is true. The question is instead

23 D. McClean, Transnational Organized Crime. A Commentary on the UN Convention and its Protocols, Oxford, Oxford University Press, 2007, p. 15.

24 A. Jordan, p. 9. Although this is an annotated guide to the Palermo Protocol, the purpose of which is to be used as a tool to assist advocates in the development of a human rights framework for national anti-trafficking laws and policies, it is far from obvious that all interested parties have read it or even know of its existence. 
answered in the official Legislative Guide to the convention and its protocols (in Paragraph 18 of Part 1 and Paragraph 25 of Part 2 of the Legislative Guide ${ }^{25}$ ). Paragraph 18 of Part 1 of the Legislative Guide reads as follows:

[.... In other words, in domestic law, the offences established in accordance with the Convention of participation in an organized criminal group, corruption, money-laundering and obstruction of justice and the Protocol offences of trafficking in persons, smuggling of migrants and trafficking in firearms must apply equally, regardless of whether the case involves transnational elements or is purely domestic. ${ }^{26}$

The question is why this issue has not been properly resolved in the Palermo documents. Arguably, one should be able to understand the role of the elements of transnationality and the involvement of a criminal group without being forced to consult the preparatory works, annotated guides, and the like. It should also be noted that there might be a risk that not all interested parties are aware of the preparatory works' existence.

It seems as if the Swedish legislator has been aware of the Legislative Guide to the Palermo Convention and its protocols. In the preparatory works to the first provision on trafficking (2002), it is acknowledged that trafficking might take place within a single country. ${ }^{27}$ This is later restated in the preparatory works to the provision from 2004. ${ }^{28}$ This awareness on behalf of the Swedish legislator might, however, be connected to the facts that preparatory works are a common concept (and a source of law) in the Swedish legal system and that Swedish lawyers consult these in instances of interpretation of both national and, where available, international law.

In Poland, by contrast, preparatory works ${ }^{29}$ are not considered a source of law. It is therefore not difficult to imagine that Polish lawyers are not as accustomed to consulting (international) preparatory works as their Swedish counterparts. In this context it should be noted that of the four authoritative

25 See more on Paragraph 25 of Part 2 of the Legislative Guide under the section on the Palermo Protocol.

26 Legislative Guide, Part 1, Paragraph 18, p. 11.

27 Prop. 2001/02:124, p. 8.

28 Prop. 2003/04: 111, p. 48.

29 In Poland, preparatory works in the Swedish sense of the word do not exist. There are occasional comments made by legal scholars during the drafting process, but these are not seen as a source of law or even as a means of interpreting the law. They are rarely used in doctrine and are not routinely referred to in case law. 
commentaries to the Polish Criminal Code consulted by the author only one actually mentions the Palermo Protocol.

In this context, Article 34, Paragraph 3 of the Palermo Convention, which stipulates that domestic measures may be broader in scope and more severe than those stated in the protocols, should be noted. The Palermo documents thus only impose a minimum standard. However, it should be borne in mind that this does not solve the problem per se. It simply allows countries to take tougher measures against trafficking. Below, the Palermo Protocol and the international definition of trafficking are discussed.

\section{Palermo Protocol - The Negotiation Process}

\section{Introduction}

It should be noted that the Palermo Protocol is, first and foremost, a law enforcement instrument. From an individual-centered perspective, a more rights-oriented instrument might have been a better option. However, the need for creating an anti-trafficking instrument developed from the desire of governments to counter transnational organized crime. Not surprisingly, a law enforcement tool with rather weak language on human rights protections was drafted. ${ }^{30}$ As has been mentioned before, in 1992 the UN established a Commission on Crime Prevention and Criminal Justice which soon decided to tackle the issue of transnational organized crime. On the recommendation of the Commission, a World Ministerial Conference on this subject was held in Naples in 1994. At this point, the characteristics of the new threat were discussed, addressing issues such as failed states, globalization, and the increasing element of internationality in organized crime which manifested itself in the form of various trafficking crimes. ${ }^{31}$

This sparked the discussions on a new instrument. Eventually Poland proposed an elaboration of a new convention on organized crime and submitted a draft. At first, the idea was to include various offences in one document, but as time went by other proposals were made. Eventually a decision was taken in a General Assembly resolution to establish an openended intergovernmental Ad Hoc Committee. The first task of the committee was to submit a draft of a convention against transnational organized crime. The second task was to discuss the elaboration of international

\footnotetext{
$30 \quad$ A. Jordan, preface.

31 D. McClean, 2007, p. 3.
} 
instruments addressing, among other things, trafficking in women and children. ${ }^{32}$

In effect, little preliminary work was actually carried out by the Ad Hoc Committee on the draft protocols. Suggestions were instead submitted by individual countries, among them the United States and Argentina.

Over one hundred states were represented at the sessions of the committee. In addition, the committee also held parallel informal meetings. NGO representatives were invited to participate, even though the topic of the negotiations was not seen as pertaining directly to human rights law. Simply put, three different perspectives or approaches that affected the final draft can be distinguished. These include a migration perspective, a criminal law perspective that focuses on the prosecution of traffickers, and a human rights perspective. ${ }^{33}$ The last perspective can, in the main, be divided into two sub-perspectives or groups. There was a lack of consensus between the two groups representing the human rights perspective, which basically concerned two vastly opposed views on prostitution.

The first group, the Human Rights Caucus, led by the Global Alliance Against Trafficking in Women (GAATw) and the International Human Rights Law Group (IHRLG) advocated for a broad definition of trafficking that covered all its forms such as forced labour and servitude irrespective of the nature of the work or services provided or the gender of the trafficked person. The definition was, however, to exclude voluntary prostitution. Trafficking would be defined by the presence of, inter alia, coercion or any other form of abuse with regard to recruitment or the conditions of work in the country of destination.

Additionally, the group strived for the inclusion of human rights protections for trafficked persons regardless of their willingness to act as witnesses for the prosecution. These rights would include the right to a safe shelter; social, medical and legal assistance; the ability to sue for back wages and damages; and residency and working permits during judicial proceedings. It was also noted that victims of trafficking are often treated as criminals for selling sex, begging on the streets, violating labour laws, etc. One of the aims of the GAATw-led coalition was therefore to include an anti-discrimination clause to ensure that trafficked persons are not subjected to discriminatory treatment in law or in practice.

The second group represented by the Coalition against Trafficking in Persons (CATW) and its partners, inter alia, the European Women's Lobby (EWL) and

32 Resolution 53/111 of December 1998 as referred to in D. McClean, 2007, p. 9.

33 J. Westerstrand, "Mellan mäns händer. Kvinnors rättssubjektivitet, internationell rätt och diskurser om prostitution och trafficking”, Uppsala universitet, 2008, p. 190 f. 
the International Abolitionist Federation (IAF) regarded prostitution as a violation of human rights that should be abolished. According to this group not even an adult is believed to be able to genuinely consent to engage in prostitution. Improper means are irrelevant since there is no distinction between forced and free prostitution. Consequently, the group sought to include all prostitution as well as other sex work in the definition of trafficking in the Palermo Protocol irrespective of conditions (improper means) or consent of the victim. ${ }^{34}$ The Coalition Against Trafficking in Women organized 140 NGOS into the International Human Rights Network. It advocated for a definition of trafficking that would protect all victims of trafficking, not just those who could prove they had been forced. An additional goal was to create protection mechanisms for trafficked women and children and strict and consistent measures of prosecution for traffickers. Focus was on the demand aspect of trafficking, which was described as having previously been perceived as an invisible link in the trafficking chain. ${ }^{35}$ As has been mentioned above, what the group actually wanted was to criminalize all trade measures undertaken with the purpose of exploitation irrespective of whether or not improper means had been used. The argument raised by some states that supported this view was that the element of coercion would be difficult to prove in court.

By contrast, the GAATW presented their own definition of trafficking, which they claimed was based on their collective experience in this area. According to the organization, trafficking involves the criminal manipulation of persons who want or need to migrate in hopes of a better future. Trafficking is said to be the result of a combination of the victims' desires to migrate, organized crime, and restrictive immigration laws in the countries of destination. According to the GAATW trafficking includes all acts (including attempts) aimed at recruitment, transportation within and across borders, purchase, sale, transfer, receipt or harbouring of a person involving the use of deception, coercion (including the use or threat of force or the abuse of authority) or debt bondage for the purposes of placing or holding such person, whether for pay or not, in servitude (domestic, sexual or reproductive), in forced or bonded labour, or in slavery like conditions, in a community other than the one in which such person lived at the time of the original deception, coercion or debt bondage. ${ }^{36}$

34 "History", cATw, http://www.catwinternational.org/WhoWeAre/History, (accessed 19 May 2014).

35 "Guide to the New UN Trafficking Protocol", CAATw, European Women's Lobby, AFEM, p. 3, t http://www.catwinternational.org/Content/Images/Article/83/attachment. pdf, (accessed 19 May 2014).

36 "Human Rights and Trafficking in Persons: A Handbook", GAATw, 2000, pp. 26-27. 
This group ultimately held that if prostitution was forced it would be categorized as trafficking and consent of the victim would never arise as a separate matter. The presence of improper means would thus preclude possible consent. GAATW also highlighted that the victims should not be blamed for their choices, stating that GAATW defends the safety and rights, including the right to self-representation and organization, of all migrants and their families against the threats of an increasingly globalized and informal labour market. $^{37}$

The GAATW also argued that the abolitionist approach to prostitution views not only prostitution as morally deviant but also some of the women involved in this trade as both deviant, fallen, and helpless. ${ }^{38}$ Other opponents of the abolitionist approach argued that the approach fails to see trafficked women as individuals capable of making autonomous decisions. Since it is impossible to find a clear-cut victory for any of the parties to this dispute, the trafficking definition of the Palermo Protocol is said to be a compromise. ${ }^{39}$

The dispute between the two groups referred to above is still a heated and very complicated debate. Some argue that in this context it is useful to distinguish between choice and agency. While a person in a vulnerable position might not have a choice but to agree to being trafficked, she still possesses the agency to act. ${ }^{40}$ While some research indicates that legalized prostitution de facto increases trafficking, ${ }^{41}$ the question still remains whether it was the best choice to explicitly state in the trafficking provision that consent is irrelevant (only) when any of the improper means have been used. This will be more thoroughly discussed in the section on consent.

37 "Basic Principles of GAATw", http://www.gaatw.org/index.php?option=com_content\&vie $\mathrm{w}=$ article\&id=94\&Itemid=47, (accessed 19 May 2014).

38 "Human Rights and Trafficking in Persons: A Handbook", p. 61 f.

39 D. McClean, p. 322

40 K. Touzenis, "Trafficking in Human Beings. Human Rights and Trans-national Criminal Law, Developments in Law and Practices", Unesco Migration Studies 3, 2010, p. 35, http:// unesdoc.unesco.org/images/oo18/o01883/188397e.pdf, (accessed 19 May 2014).

41 See E. Neumayer, A. Dreher, S.Y. Cho, "Does Legalized Prostitution Increase Human Trafficking?", World Development, vol. 41, 2013, pp. 67-82, http://www.sciencedirect.com/ science/article/pii/So305750X12001453\#, (accessed 19 May 2014), where the authors argue that although legalization of prostitution has led to a preference among sex buyers for non-trafficked prostitutes, this effect has been smaller than the demand for foreign sex workers. When prostitution is legalized, the demand for sex workers increases. This demand, however, is not met by voluntary (domestic) sex workers, which, in effect, increases trafficking flows for sexual exploitation. 
Another important question is how the dispute described above affected the definition of trafficking that finally emerged. Some scholars argue that as a result of the conflict described above, the NGOs were not able to counter the government representatives' focus on repressive measures against illegal migration and organized crime, thus failing to strengthen the victims' human rights. ${ }^{42}$ However, we cannot know for sure if the situation would have been different, i.e., if we would have a better definition of trafficking and a more human rights oriented document if the NGOs mentioned above instead of carrying on this dispute would have cooperated. We must still keep in mind that the Palermo documents were a state effort aimed at countering organized crime. In effect, the state representatives agreed on a common denominator, namely criminal measures.

Below, the general articles of the Palermo Protocol will be discussed.

\section{The Palermo Protocol-General Rules}

The starting point in the fight against human trafficking is the implementation of the Protocol to Prevent, Suppress and Punish Trafficking in Persons, especially Women and Children, which supplements the United Nations Convention against Transnational Organized Crime. ${ }^{43}$

The statement above was made by the UNODC and reflects the understanding of the UN on the importance and potential of the Palermo Protocol in the fight against trafficking in human beings.

As has been mentioned in the introduction, the main purposes of the Palermo Protocol are three. Firstly, state signatories to the document are to criminalize trafficking in human beings in their national legislations and to establish proper penalties for this offence. Secondly, states should promote international cooperation. Thirdly, the signatories are to consider offering protection and assistance to victims of trafficking. The first purpose is expressed in mandatory terms. The other two, however, are facultative.

Article 4 of the Palermo Protocol stipulates the scope of the protocol's application. The provision reads as follows:

This Protocol shall apply, except as otherwise stated herein, to the prevention, investigation and prosecution of the offences established in

M. Ditmore, M. Wijers, "The Negotiations on the UN protocol on Trafficking in Persons", NEMESIS, no. 4, 2003, pp. 79-8o.

“Trafficking in Persons. Global Patterns”, unODC, April 2006, p. 12. 
accordance with Article 5 of this Protocol, where those offences are transnational in nature and involve an organized criminal group, as well as to the protection of victims of such offences.

Article 5 of the protocol requires states to criminalize trafficking in human beings as well as and when applicable ${ }^{44}$ attempt, preparation, and organizing of this crime. Trafficking can be criminalized by means of creating a single offence or a combination of offences. What matters is that the provision[s] address, at a minimum, the full range of conduct covered by the trafficking definition of the protocol. Article 5 reads as follows:

1. Each State Party shall adopt such legislative and other measures as may be necessary to establish as criminal offences the conduct set forth in Article 3 of this Protocol, when committed intentionally.

2. Each State Party shall also adopt such legislative and other measures as may be necessary to establish as criminal offences:

(a) Subject to the basic concepts of its legal system, attempting to commit an offence established in accordance with Paragraph 1 of this Article;

(b) Participating as an accomplice in an offence established in accordance with Paragraph 1 of this Article; and

(c) Organizing or directing other persons to commit an offence established in accordance with Paragraph 1 of this Article.

The wording of Article 4, notably the part on the transnational nature of the crime and the involvement of an organized criminal group in its commission, reinforces the view that the protocol is only applicable in cases where these circumstances are present. However, according to Article 1, Paragraph 2 of the protocol, the provisions of the Palermo Convention shall apply mutatis mutandis to the protocol. In principle this means that if the spirit of the convention is to forego the requirement of transnationality when drafting national criminal legislation in this area, the meaning of the protocol should be the same.

44 States are required to criminalize attempts only if it is compatible with the basic principles of the relevant legal system. Generally, the drafters of the protocol agreed that attempts to commit trafficking should be criminalized. Nevertheless, the concept of attempt does not apply in the criminal justice systems of some of the state signatories to the Palermo documents. Consequently, the disclaimer subject to the basic concepts of its legal system was incorporated into Article 5 of the protocol. See the Legislative Guide, Part 2, Paragraph 41. 
As we have already seen, Article 34, Paragraph 2 of the Palermo Convention is to be interpreted in such a way that the element of transnationality is not necessary in cases of criminalization and that also so-called internal trafficking is to be (the convention uses the words state parties shall...) criminalized by state parties.

In other words, in domestic law, the offences established in accordance with the Convention of participation in an organized criminal group, corruption, money-laundering and obstruction of justice and the Protocol offences of trafficking in persons, smuggling of migrants and trafficking in firearms must apply equally, regardless of whether the case involves transnational elements or is purely domestic. ${ }^{45}$

In line with this argument, Part 2, Paragraph 25 of the Legislative Guide to the Palermo Protocol reads as follows:

It is important for drafters of legislation to note that the provisions relating to the involvement of transnationality and organized crime do not always apply...[I]t is important to emphasize that, for example, Article 34, Paragraph 2, of the Convention provides that legislators must not incorporate elements concerning transnationality or an organized criminal group into domestic offence provisions... In the case of trafficking in persons, domestic offences should apply even where transnationality and the involvement of organized criminal groups do not exist. ${ }^{46}$

The element of transnationality constitutes one of the criteria for applying the Palermo Convention and its protocols to the extent that it concerns international cooperation. Transnationality should, however, not form a prerequisite of national trafficking offences and is, by the same token, not required as proof in national prosecution of trafficking cases. The same applies to the criterion of involvement of an organized criminal group. Consequently, offences established in accordance with the protocol should apply equally irrespective of whether they were committed by individuals associated with an organized criminal group or by individuals working independently. This is clearly expressed in the official interpretative notes (made by drafters of the Palermo documents during the drafting process),

45 Legislative Guide, Part 1, Chapter 2, Paragraph 18, p. 11.

46 Legislative Guide, Part 2, Chapter 1, Paragraph 25, p. $25^{8}$. 
as summarized in the Legislative Guides to the Palermo Convention and its protocols. ${ }^{47}$

As has been mentioned above, the Swedish state seems familiar with the preparatory works to the Palermo Protocol. The Swedish preparatory works to the trafficking provision from 2004, e.g., clearly state that there is no requirement in the Palermo Protocol to incorporate into national criminal legislation an element of transnationality. ${ }^{48}$ The question is whether the same can be said about other states. In the author's opinion, there is a risk that some states not having the same tradition of preparatory works or experience with interpreting and applying international law might find this problematic. Below, the international definition of trafficking will be analysed.

\section{Article 3 of the Palermo Protocol - The Definition of Trafficking Introduction}

According to some experts, the trafficking definition of the Palermo Protocol has been widely embraced by states and the international community alike. ${ }^{49}$ However, important questions remain about certain prerequisites of the definition, as well as its application in domestic criminal law. Reportedly, there is a conflict between those who support a restrictive interpretation of the crime of trafficking, and those who advocate for its expansion. The complex wording of the Palermo Protocol's definition of trafficking is partially blamed for this development. ${ }^{50}$ Article 3 of the Palermo Protocol reads as follows:

For the purposes of this Protocol:

(a) "Trafficking in persons" shall mean the recruitment, transportation, transfer, harbouring or receipt of persons, by means of the threat or use of force or other forms of coercion, of abduction, of fraud, of deception, of the abuse of power or of a position of vulnerability or of the giving or receiving of payments or benefits to achieve the consent of a person having control over another person, for the purpose of exploitation. Exploitation shall include, at a minimum, the exploitation of the prostitution of others or other forms of sexual exploitation, forced labour or services, slavery or practices similar to slavery, servitude or the removal of organs;

47 See Article 34, Paragraph 2 of the Palermo Convention and Paragraph 59 of the Interpretative Notes, $\mathrm{A} / 55 / 383 /$ Add.1.

48 Prop. 2003/04: 111, p. 32.

49 "Abuse of a Position of Vulnerability and Other 'Means' within the Definition of Trafficking in Persons", Issue Paper, UnODC, 2013, p. 1.

5o Ibid. 
(b) The consent of a victim of trafficking in persons to the intended exploitation set forth in subparagraph (a) of this article shall be irrelevant where any of the means set forth in subparagraph (a) have been used;

(c) The recruitment, transportation, transfer, harbouring or receipt of a child for the purpose of exploitation shall be considered "trafficking in persons" even if this does not involve any of the means set forth in subparagraph (a) of this article;

(d) "Child" shall mean any person under eighteen years of age.

There is no obligation on state signatories to also criminalize the individual elements of trafficking such as abduction or forced prostitution. ${ }^{51}$ However, it is up to the states to adopt such provisions if they wish to do so. Consequently, the abovementioned requirement to criminalize trafficking concerns the crime as a combination of constituent parts and not the individual elements. If one of the listed measures is combined with any of the listed means and carried out for any of the listed purposes, the conduct must be qualified as trafficking. It is important to note that trafficking is completed at an early stage, even before an actual exploitation has taken place..$^{52}$

Thus, trafficking is considered to be a multi-layered offence, one that can be divided into three constituent parts. These include measures, means, and purposes. Starting with the part on measures, they will be discussed in more detail below.

\section{Measures}

The first part of the definition of trafficking deals with various trade measures. Each person that facilitates a trade measure against another person might be guilty of trafficking. In a similar vein, the trafficked person can become victim of several crimes committed by several perpetrators.

The trade measures include recruitment, transportation, transfer, harbouring, and receipt. ${ }^{53}$ There is a wide range of possible methods that the trafficker can use. They often vary depending upon the cultural context and the geographical setting as well as on the individual circumstances of the potential victim and the financial possibilities of the trafficker. In most cases, however,

51 This especially pertains to the issue of prostitution which is considered to fall outside of the scope of the Palermo documents. See the Interpretative Notes, Paragraph 64, A/55/383/Add. 1 .

52 Legislative Guide, Part 2, Paragraph 33, pp. 268-269.

53 These measures are not further elaborated upon, neither in the Interpretative Notes nor in the Legislative Guide. 
the conduct starts with some sort of recruitment. Sometimes traffickers operate alone, and sometimes they are involved in larger networks where different persons specialize in different links of the trafficking chain. Statistics also indicate that the number of female traffickers is on the increase. Sometimes, former victims of trafficking in human beings, in particular for the purpose of sexual exploitation, eventually become traffickers. ${ }^{54}$ Women often rank low in the trafficking rings and are usually responsible for tasks that make them more exposed to the risk of detection and prosecution than those of male traffickers. This development is especially prevalent in Eastern Europe and Central Asia, where more than three fourths of those convicted of trafficking in persons offences are women. ${ }^{55}$

Apart from the obvious form of the giving and receiving of payments, it is possible to commit a trafficking offence by harbouring or in one way or another transporting the trafficked person. Sometimes people are smuggled across borders, and sometimes they travel with legitimate or forged documents. Along the way, there can be several steps involving multiple perpetrators. The journey ends in the country of destination, at which point the victim is delivered to the person who will be responsible for organizing the subsequent exploitation.

A conduct can only be described as trafficking if combined with certain means and carried out for a specific purpose. Below, the means listed in Article 3 of the Palermo Protocol will be touched upon.

\section{Means}

In order for the conduct to be considered trafficking in human beings, one of the means set forth in Article 3 of the Palermo Protocol must by employed by the trafficker unless the victim is a minor. These include the use of force or the threat thereof, other forms of coercion, of abduction, of fraud, of deception, of the abuse of power or of a position of vulnerability, or of the giving or receiving of payments or benefits to achieve the consent of a person having control over another person. Only some of these means have been clarified in the Interpretative Notes. This is probably due to the fact that most state signatories already had provisions and case law concerning the majority of the improper means. The preparatory works to the Palermo Protocol, however, shed some light on the notion of vulnerability.

54 "Trafficking in Human Beings", Eurostat Methodologies and Workingpapers, European Commission, 2013, p. 67 .

55 “Global Report on Trafficking in Persons", 2012, UnODC, p. 11. 
On the one hand, the preparatory works refer to existent legislations of different state signatories. In many countries pregnant women and drug addicts, e.g., are considered to be in vulnerable positions. The preparatory works also point to country-specific solutions, e.g., the case of Bulgaria, where abuse of power in relation to the victim is also considered a form of a vulnerable position.

On the other hand, the Interpretative Notes express their own understanding of the concept of vulnerability which is said to refer to any situation in which the person involved has no real and acceptable alternative but to submit to the abuse involved. ${ }^{56}$ The definition acknowledges that many trafficked people are simply following orders of those close to them, such as a parent, a spouse or a community leader. These people might, due to legal or cultural reasons, lack the possibility of refusing. ${ }^{57}$ However, the intentions of the drafters of the Protocol with respect to a vulnerable position of the victim are said to be unclear, as there seems to be no explanation for why the concept was included, apparently at the last minute. A possible reason for including a wide range of overlapping means in the definition is said to have been motivated by an ambition to ensure that all the different ways by which an individual can be placed in a state of exploitation were covered. ${ }^{58}$ However, none of the means stated in the protocol's definition of trafficking are defined. According to the preparatory works, the prerequisite of 'abuse of a position of vulnerability' is to be interpreted as referring to 'any situation in which the person involved has no real and acceptable alternative but to submit to the abuse involved'. However, no further guidance is provided on how this concept is to be applied in practice. .9

There is also a Note on illegal adoptions, which might pertain to the means of the giving and receiving of payments in order to obtain consent from a person having control over another person. If the purpose of the illegal adoption amounts to a practice similar to slavery as defined in Article 1, Paragraph (d) of the Supplementary Convention on the Abolition of Slavery, the Slave Trade, and Institutions and Practices Similar to Slavery, the conduct will be considered trafficking. ${ }^{60}$ It is worth noting that transactions for non-commercial purposes are not viewed as trafficking. Naturally, most countries have other

\footnotetext{
56 Interpretative Notes, A/55/383/Add.1, Paragraph 63.

57 A. Jordan, 2002, p. 4.

$5^{8}$ "Abuse of a Position of Vulnerability and Other 'Means' within the Definition of Trafficking in Persons", p. 3.

59 Ibid, p. 3.

$60 \quad$ Interpretative Notes, A/55/383/Add.1, Paragraph 66.
} 
provisions that criminalize adoptions for commercial purposes. However, from a strictly symbolic point of view, the giving or receiving of excessive payments for the purpose of adoption might be considered a form of slavery in cases where the child is traded as a mere commodity.

\section{Purpose}

The third requirement for the conduct to be considered trafficking in human beings is the purpose of the act which should be exploitative in nature, including, at a minimum, the exploitation of the prostitution of others or other forms of sexual exploitation, forced labour or services, slavery or practices similar to slavery, servitude, or the removal of organs. The wording of Article 3 (a), i.e., the phrase for the purpose of, implies that direct intent to exploit is necessary at all stages of the trafficking chain. This forms an ulterior intent requirement, which means that there must be direct intent to fulfil a certain purpose, which is exploitation. This is true if the trafficker is to be convicted of trafficking as a principal perpetrator. In other cases, the rules on complicity might become applicable.

In this context, it seems fruitful to consider the purpose of the Palermo Protocol which is to criminalize all links of the trafficking chain including recruitment and transportation. Intuitively, one might believe that the party responsible for the subsequent exploitation must have intent to exploit the victim and that this is enough for the conduct to be considered trafficking. It seems sufficient that the other parties have intent in relation to their own conduct, such as recruitment of the victim and a specific improper means, and intent (but not necessarily direct intent) in relation to the intent of the person responsible for the subsequent exploitation.

However, it is questionable if this is the case. The wording of Article 3 suggests that every person must have the specific purpose of exploitation. As we shall see, this constitutes a weakness in the international definition. It is important to note that there are no clear answers to this question of the purpose of the perpetrator in the Palermo documents or the preparatory works thereto. In effect, this has created certain problems on the national level. These will be addressed in the chapters containing the country analyses.

Forms of sexual exploitation other than in the context of trafficking in persons are not covered by the Palermo Protocol. The Interpretative Notes state that:

The travaux préparatoires should indicate that the Protocol addresses the exploitation of the prostitution of others and other forms of sexual exploitation only in the context of trafficking in persons. The terms 'exploitation of the prostitution of others' or 'other forms of sexual 
exploitation' are not defined in the Protocol, which is therefore without prejudice to how State Parties address prostitution in their respective domestic laws. ${ }^{61}$

The abovementioned statement is a way of reconciling various national views on prostitution, notably the discussion on forced versus voluntary prostitution. In that context, some states have legalized the practice and some, like Sweden, have criminalized, or are currently discussing the criminalization of, the purchasing of sexual services.

The concepts of forced labour, servitude, etc., are not defined in the Palermo Protocol. Instead, reference is made in the Legislative Guide to existent international documents in relevant areas such as the ILO Convention concerning Forced or Compulsory Labour. With regard to the practice of trafficking in human organs, there is a Note concerning the removal of a child's organs for legitimate medical or therapeutic reasons. This cannot form an element of trafficking if valid consent has been obtained before the procedure from the child's parent or legal guardian. ${ }^{62}$

\section{Intent of the Perpetrator}

In order for an offence to be viewed as trafficking under the Palermo Protocol, general intent in relation to the act must be established. This means intent in relation to a trade measure and specific means. In the cases of underage victims, intent with regard to the victim's age must also be established. In these cases, intent based on indifference or probability should arguably be enough. This is the result of the fact that in many instances traffickers are not interested in the age of the victim and do not undertake the necessary measures to gain this information. In other cases, underage victims are what the traffickers are looking for. Also, when arranging travel, either by having access to the victim's ID or in the act of falsifying documents, knowledge of the victim's age seems apparent.

According to the Palermo documents, only intentional conduct is to be criminalized.

All of the criminalization requirements of the Convention and Protocols require that the conduct of each offense must be criminalized only if committed intentionally. Thus, conduct that involves lower standards, such as negligence, need not be criminalized. ${ }^{63}$

61 Interpretative Notes, A/55/383/Add.1, Paragraph 64 .

62 Interpretative Notes, $\mathrm{A} / 55 / 383 /$ Add.1, Paragraph 65.

63 Legislative Guide, Part 2, Paragraph 45(d), p. 267. 
The question of what is meant by intentional conduct arises. Does the term only exclude negligent acts or does it also require direct intent, in effect excluding other forms of intent such as indirect intent (intent based on knowledge) and dolus eventualis (intent based on indifference or probability)? Arguably, other forms of intent than direct intent should be possible. Naturally, there is a certain margin of appreciation concerning national concepts of intent.

Also, the Interpretative Note reads that state parties need not criminalize negligence, which means that they are not prohibited from criminalizing negligent conduct should they wish to do so. In addition, Article 34, Paragraph 3 of the Palermo Convention explicitly allows for measures that are more strict or severe than those suggested by the convention and its protocols. Again, this does not solve the problem as we do, e.g., not know if national provisions requiring direct intent with respect to all elements of the act of trafficking would meet the requirements of the protocol.

As has been mentioned above, in addition to general intent with regard to the unlawful act (to at least one trade measure and improper means), specific purpose to exploit the victim is also necessary. This is one of the integral prerequisites of the definition of trafficking.

\section{Consent}

Once it is established that deception, coercion, force, or other of the means listed in Article 3, subparagraph (a) have been employed, possible consent is precluded or irrelevant, and by the same token, genuine consent can never be combined with any of the prohibited means. ${ }^{64}$

Yet, the issue of consent was, as has been mentioned above, fiercely debated during the negotiation process of the Palermo Protocol. To summarize this debate, one group (the Human Rights Caucus led by the GAATw) argued that improper means would preclude consent and that there therefore was no need to explicitly state that consent was irrelevant. The other group (the CATw-led network of NGOs) held that it should be highlighted that even if the victim consents at some stage, trafficking might still take place. It also held that possible consent should not be used as a defence by defendants in trafficking cases. Again, what the debate actually boiled down to was the issue of forced versus voluntary prostitution.

According to some scholars, consent is basically an issue in the protocol because the document is thought to protect the stereotypical coerced innocent. By contrast, a male economic migrant is perceived to have voluntarily and consciously chosen smuggling as a means of facilitating entry into the

64 Legislative Guide, Part 2, Chapter 2, Paragraph 37, p. 254. 
destination country of his choice, which in practice is not always the case. In the Palermo Protocol on smuggling the issue of consent is irrelevant. This is the result of the rather widespread belief that the stereotypical smuggled person is a rational male economic migrant, who has acted on his own and who is not under the control of others. ${ }^{65}$

The argument above seems to suggest that women should not be blamed for their choices or rather for displaying agency. The main thrust of this argument is that trafficking is possible even if the woman consented at some stage of the recruitment, i.e., if she agreed to prostitute herself. The wording that consent is irrelevant when any of the improper means has been used by the trafficker in conjunction with a specific trade measure might indicate that focus is on the initial stage of the trafficking chain. As we shall see, this has had implications on the national level. These implications can be summed up as an undue focus on the situation in the country of origin, a lack of understanding on when a legally valid consent can be obtained and withdrawn, and confusion with regard to the concepts of free choice and agency.

Even though it is important to distinguish trafficking from smuggling ${ }^{66}$ as the first is a crime against the person and the other against the state, women who have displayed some level of agency should not be treated differently than 'the coerced innocents'.

We should also keep in mind that smuggling is arguably not just a crime against the state but often also against individuals. Smugglers usually target people in vulnerable situations. This suggests that the choices of the smuggled persons are not always voluntary. At times, people agree to being transported under dangerous conditions (like containers on water), all in hope of securing a better future for themselves and possibly their families. Often the smuggled person cannot afford the trip and becomes indebted to the smuggler. Upon arrival in the country of destination, he might be forced to repay the debt, sometimes under circumstances resembling slavery or practices similar to it.

Even though the definition of smuggling does not require an element of abuse, most smuggled persons are, in one way or another, abused by the smugglers. Arguably, few would consider enlisting the help of smugglers if not truly desperate. There is not one country in the world that is not affected by the

\footnotetext{
$65 \quad$ K. Abramson, p. 479.

66 The crime of smuggling of human beings is defined in Article 3 (a) of the Palermo Protocol on smuggling. The Article reads as follows: Smuggling of migrants' shall mean the procurement, in order to obtain, directly or indirectly, a financial or other material benefit, of the illegal entry of a person into a State Party of which the person is not a national or a permanent resident.
} 
smuggling of migrants, whether as a country of origin, transit or destination for migrants smuggled by criminal networks. Smuggled migrants might be just as vulnerable to life-threatening risks and exploitation as victims of trafficking. Throughout the world, thousands of people have died during perilous transports. ${ }^{67}$

Although trafficking and smuggling constitute two different crimes, they are interesting to compare with respect to how the concepts of free choice and agency might be construed depending upon context. While the definition of smuggling reflects a rational (male) migrant who has the agency to act, the words by means of in the definition of trafficking suggest that the victim is not only to be deprived of the freedom of choice but also of her agency to act. It should be recognized that victims of both trafficking and smuggling might lack a free choice. When trafficking is concerned, victims might possess the agency to act or they might not, while in cases of smuggling they always possess this agency. Consent, however, arguably contains both concepts. The fact that a woman consents to recruitment might thus illustrate the agency to act. However, for consent to become relevant she must also have a free choice, i.e., viable options.

Victims of trafficking are often deceived about the nature of the work promised to them. Nevertheless, this does not mean that they fit the image of the 'coerced innocent'. The question is whether, as a result of this idea of a stereotypical victim, the other category of women who do decide to prostitute themselves abroad might be considered fallen and therefore less worthy of state protection. At the same time, research indicates that this particular type of victim of trafficking, i.e., older women with children (obviously sexually experienced) is growing. I will explore this question in the chapters containing the case studies.

Some might ask whether the words consent is irrelevant in the international definition of trafficking do indeed safeguard the rights of all victims because they ultimately suggest that it does not matter whether or not the victim had consented to prostitution. However, as improper means and, above all, exploitation are prerequisites of the definition, this is already evident. What seems to be the main issue here is how the concept of improper means has been construed. It is the words by means of that imply that the perpetrator must assume a very active role. Again, here certain requirements concerning agency and

67 "Assessment Guide to the Criminal Justice Response to the Smuggling of Migrants", UN, 2012, p. 1, http://www.unodc.org/documents/human-trafficking/Migrant-Smuggling/ UNODC_2012_Assessment_Guide_to_the_Criminal_Justice_Response_to_the _Smuggling_of_Migrants-EN.pdf, (accessed 19 May 2014). 
consent must be fulfilled by the woman if she is to be regarded as a victim of trafficking. A woman in an extremely vulnerable situation might not possess a free choice, which negates consent. Yet, she might still retain the agency to act and, e.g., initiate recruitment. In other words, it seems as if it does not matter whether we explicitly state that consent is irrelevant or not if we keep the wording or construction by means of. The latter suggests that some women might get blamed for displaying agency in order to change their situation and that these actions might be mistaken for free choice and consent despite the fact that the women and their situations are exploited by the perpetrator.

By focusing on the behaviour of the victim (such as possible consent, i.e., if she was influenced by any of the improper means or not) in the country of origin or during transport, transfer, etc., we risk losing track of the situation in the country of destination. This is what has happened in national court proceedings where prosecutors are required to present detailed information on the situation of the victim in the country of origin and how she behaved when the perpetrator first approached her. This creates certain difficulties as the information is located in another country. In most cases it is also impossible to tell what happened between the perpetrator and the victim.

In this context, it seems more fruitful to consider the nature of the actual exploitation. Was the victim involved in some form of procuring? Was there some form of an informal contract between the parties, allowing her to keep part of her earnings or to go home if she would decide to do so? Or was she kept under explicit or implicit surveillance? Did she have money, a passport, and knowledge of the country of destination? Was she able to communicate with other people? Was she afraid of the trafficker? Was she in a vulnerable position (both in her home country and in the country of destination)?

The focal point should be the exploitation in the country of destination, to which one cannot legally consent, or the intentions of the perpetrator to exploit a person like a commodity. Although this is arguably covered by Article 3 , as trafficking needs not to be transnational, in practice it is often neglected.

Some scholars argue that the drafters of the Palermo Protocol instead of focusing on the elements of force or deception or even the actual exploitation, the existence of which de facto precludes the possibility of consent, placed emphasis on the pros and cons of legalizing or criminalizing prostitution. It has been argued that instead of seeing the offence of trafficking as a human rights violation, the sexuality of women yet again took centre stage and that such a development not only distracts the attention from the abuse associated with the exploitation that takes place in the country of destination but also unduly limits the understanding of trafficking to offences against physically coerced women. Further, as physical coercion, threat, etc., in the country of 
origin is immensely difficult to prove in court proceedings in the destination country, a situation that can best be described as a catch-22 arises. Simply put, we have here part of the explanation for the low numbers of trafficking convictions throughout the world.

The question is if the words consent is irrelevant appearing in the international definition of trafficking might suggest that consent is possible in instances where all the relevant facts are known to the trafficked person. This is not a hypothetical question, as many people throughout the world are living under such desperate circumstances that they would prefer taking their chances as slaves abroad than remain in their current situations. Some scholars claim that in situations where the prospective migrant worker did not need convincing prior to departure, doubts might arise as to whether we are dealing with trafficking or not. This is said to be true even if the person's human rights are subsequently violated in the country of destination. In such cases, consent is said to form an important factor. ${ }^{68}$ The passage above indicates that under certain circumstances consent is indeed relevant. Of course, this is already evident from the prerequisite of improper means and its connection to the trade measures. If someone is not drawn into exploitation by means of deceit, threat, etc., then obviously there is consent, and reversely it is not possible to, e.g., consent to a lie. ${ }^{69}$ However, what we should be asking is this: Is it really necessary for an act to be qualified as trafficking to influence someone by means of deceit, threat, or any of the other improper means? In essence, the question is why the following cases would be treated differently.

In case (1) the victim is in a vulnerable situation. The perpetrator is aware of this condition and takes advantage of it by initiating recruitment (e.g., offering employment). This case might be seen as trafficking. In case (2) a woman is in a vulnerable situation, but she initiates the recruitment and the perpetrator takes advantage of the situation. The case will most probably not be seen as trafficking since it will be difficult to prove that the perpetrator influenced the woman by means of abusing her vulnerability. Arguably, both cases should be qualified as trafficking as it should not matter who initiates the procedure that aims at exploiting a person who is in a vulnerable situation.

The question of improper means and the construction by means of will be more thoroughly discussed in the chapters containing the case studies as well as in the final chapter of this work.

68 K. Touzenis, p. 35 .

69 A. Jordan, p. 7. 


\section{Situation of Child Victims}

Article 3, subparagraphs (c) and (d) of the Palermo Protocol stipulate that no improper means need be established when persons under eighteen years of age are involved. Due to their age and immaturity, children are considered to be more easily persuaded or lured into trafficking than adults and therefore the use of force or other improper means is not necessary for the offence to be considered trafficking.

Article 3 (d) clearly states that the term child shall mean any person less than eighteen years of age. The wording of the provision, which highlights the objective circumstance that someone is of a certain age, taken together with the purpose of the Palermo Protocol, which is to protect victims of trafficking, especially women and children, suggests a strict interpretation.

The preparatory works to the protocol state that in instances where the victim of trafficking is a minor, the prosecution must, in order to be able to have an act qualified as trafficking, prove action such as recruitment or transportation of the underage victim for the purpose of exploitation, but no improper means. ${ }^{70}$

In addition, intent of the perpetrator vis-à-vis the age of the victim must be established. However, in that respect intent based on indifference or dolus eventualis should arguably be enough. After all, it is not uncommon that the trafficker actually looks for an underage person. Older women are often considered liabilities since they might have contracted venereal diseases, become addicted to drugs, or had several unwanted pregnancies and sometimes illegal abortions, which all take their toll on the emotional and physical health of the women.

Article 3 of Palermo Protocol states that it is forbidden to give or receive payments or benefits to achieve the consent of a person having control over another person for the purpose of exploitation. This part of Article 3 primarily applies to parents or legal guardians and children, other cases could involve people with disabilities or drug addicts who, through their addiction, are controlled by other people. Article 3 does not mention absolute control or that control must be transferred to the trafficker from the person having control over the victim. It is enough that the trafficker acquires consent of the person in control to take the victim. In the case of minors, this control seems even more implied as the age difference between the perpetrator and the victim automatically places the latter in an inferior position. The concept of control usually has a well-established meaning in national legal terminology, which is problematic for the consistent implementation of the Palermo Protocol. 


\section{Internal Trafficking}

According to international estimates, most of the trafficking victims detected around the world were foreign nationals in their country of exploitation. However, about one in every four victims detected between 2007 and 2010 was a national of the country where the exploitation took place. The crime of trafficking in human beings may suggest that the victim is moved across borders. However, this is not always the case. ${ }^{71}$ Domestic or internal trafficking not only exists but seems to be increasing. The phenomenon usually mirrors countries' varying social and criminal contexts. In some countries it might reflect socioeconomic differences, e.g., between cities and rural areas. The patterns of domestic trafficking might also indicate certain sociocultural conditions, e.g., when it comes to the occurrence of victims exploited in child labour. ${ }^{72}$

In this context it is important to note two things: Firstly, that the Palermo Protocol is to be applied also with regard to domestic trafficking, and secondly, that the current focus on the initial stage of the trafficking chain, and thus the transnational element of the crime, is uncalled for and should be nuanced by means of acknowledging trafficking as a complex phenomenon. The core of the crime is not constituted by border crossing or even movement, although the very word trafficking might imply so, but instead by the abuse and violation of a person's human rights.

\section{Summary}

The term trafficking in persons can be misleading: it places emphasis on the transaction aspects of a crime that is more accurately described as enslavement. Exploitation of people, day after day. For years on end. ${ }^{73}$

Turning now to summarize, the findings can be categorized according to the following.

Firstly, there is a lack of consistency between the Palermo documents and the preparatory works thereto. This regards the issues of border crossing and the involvement of an organized criminal group as possible prerequisites of the trafficking crime. If just the Palermo Convention and the adjoining protocols are studied, it seems as if the elements above are required as prerequisites of a trafficking provision. However, if the documents are read together

\footnotetext{
71 "Global Report on Trafficking in Persons", UnOdC, 2012, p. 49 f.

72 Ibid, p. 51.

73 "Global Report on Trafficking in Persons", UnOdC, 2009, p. 6.
} 
with the preparatory works thereto it becomes clear that these requirements do not, or rather should not, apply when criminalizing trafficking on the national level. Since not all interested parties are aware of the preparatory works to the Palermo documents, this might create certain problems concerning the practical implementation of the international definition of trafficking on the national level.

Secondly, there is the issue of the Palermo Protocol's historical and cultural context. The definition of trafficking of the Palermo Protocol has arguably been influenced by previous documents in this area as well as by the overall discourse on trafficking. The latter is in turn affected by past experiences and ideas in this field. One of these ideas is the concept of the stereotypical trafficking victim. Arguably, this idea is present in the international trafficking definition of today. This is illustrated by the fact that improper means are connected to the trade measures and that the perpetrator must influence the victim by means of violence, deceit, etc. In other words, the perpetrator must arguably assume a very active role.

If the perpetrator is to act in a certain way, this also places specific requirements on the behaviour of the victim. If he is to be active, she must be passive. This relationship is normalized in the definition of trafficking. Anything outside of this supposed axiom is seen as an anomaly and is often held against the victim. This suggests that the behaviour of the victim in the country of origin impacts on how the act is qualified. Undue focus is put on whether the perpetrator initiated a trade measure or not, and, in a similar vein, women are blamed for displaying agency. This in its turn suggests that undue attention is given to the situation in the country of origin as opposed to the abuse in the country of destination.

To summarize, the perpetrator must be aware of the victim's vulnerable situation and actively abuse it. This means that it is usually not enough to abuse an opportunity, i.e., that a person is in a vulnerable position, but the perpetrator must also make a person agree to a certain measure by means of abusing her vulnerable position. He must also understand that it is this position that forces the victim to accept his offer. In reality, traffickers intentionally target the weakest members of society. It might thus be questioned whether the trafficking definition of the Palermo Protocol is sensitive to the mechanisms of the practice of human trafficking. The definition is sometimes said to contain too many elements that must be proven by national prosecutors. ${ }^{74}$ This does in fact make the definition quite opaque and in-effectual. This line of argument corresponds to the comment above made by the UNODC, according to which 
the term trafficking in persons can be misleading as it places emphasis on the transaction aspects of a crime that is more accurately described as enslavement.

Ultimately, it all boils down to the following question. Is it necessary to include the wording by means of in the definition of trafficking? In other words, should it not be enough for the perpetrator to abuse another person's vulnerability for an act to be qualified as trafficking? If abuse of another person's vulnerability, irrespective of whether the woman had displayed agency or not (e.g., by initiating recruitment or contemplating prostitution as a means of escaping a difficult situation), was made the focus of the international definition of trafficking, we might avoid having a situation where women are divided into different categories and where some victims enjoy less protection than others based on how they behaved prior to the exploitation. It might also solve the problem of evidence in trafficking cases if courts were to consider the nature of the exploitation and not the means or measures by which a victim was essentially enslaved.

The current international definition of trafficking instead focuses more on the various trade measures and means used by traffickers at the initial stage of the trafficking chain than on the actual abuse associated with the crime.

Thirdly, the wording of Article 3 suggests that the perpetrator must act with a specific purpose to exploit the victim. The question is what happens in instances where the trafficker does not desire the exploitation per se but rather to receive remuneration. Although most traffickers act for financial gain, national laws might fail to recognize this as trafficking. In much legislation, including that of Sweden, Poland, and Russia, the words for the purpose of imply that the perpetrator must act with direct intent to exploit the victim. If such purpose cannot be established, the behaviour will not be qualified as trafficking. It might, however, be qualified as complicity. ${ }^{75}$

Fourthly, both the issue of intent of the perpetrator and consent of the victim might be resolved if focus was placed on the actual or planned exploitation. Arguably, it should not matter why you are exploiting someone or why you have contributed to such exploitation, i.e., whether it is in order to earn money or to derive some sort of sick pleasure from it. The outcome is the same. Another human being is being robbed of her dignity and basic human rights.

In this context, possible consent of the victim as well as the means and measures by which the exploitation is facilitated are arguably given too prominent of a role. The inclusion of the words consent is irrelevant in Article 3 of the

75 In some cases, a person with intent to earn money but not to exploit the victim might be seen as an accomplice to the crime. See more on this in the relevant country chapters. 
Palermo Protocol is not clearly discussed by any of the Palermo documents, nor is the prerequisite by means of, i.e., the process by which the perpetrator undertakes a measure, combined with one or several of the improper means, which is aimed to affect the disposition of the victim. This has led to a situation where some victims might be seen as less worthy of protection, e.g., if they have initiated the recruitment, contemplated prostitution as a way of escaping a difficult situation, etc.

In many instances, people choose exploitation before starvation, which has prompted some to argue that such cases might not be seen as exploitation. However, the fact that a person would starve to death had he not decided to enter into forced labour does not mean that exploitation has not taken place. The person in question is still treated as a slave, no matter what the circumstances were that influenced his choice.

The following chapters will indicate how the international definition of trafficking has affected national trafficking laws. The process of implementation will also be discussed. This will indicate country-specific challenges and answer the question whether certain difficulties on the national level are attributable to the original source, i.e., the trafficking definition of the Palermo Protocol. 